\title{
Cannabinoids Stimulate the TRP Channel-Dependent Release of Both Serotonin and Dopamine to Modulate Behavior in C. elegans
}

\author{
Mitchell Oakes, ${ }^{\star} \odot$ Wen Jing Law, ${ }^{*}$ and $\odot$ Richard Komuniecki \\ Department of Biological Sciences, University of Toledo, Toledo, Ohio 43606-3390
}

Cannabis sativa alters sensory perception and exhibits potential medicinal benefits. In mammals, cannabinoids activate two canonical receptors, $\mathrm{CB}_{1} / \mathrm{CB}_{2}$, as well additional receptors/ion channels whose overall contributions to cannabinoid signaling have yet to be fully assessed. In Caenorhabditis elegans, the endogenous cannabinoid receptor agonist, 2-arachidonoylglycerol (2-AG) activates a $\mathrm{CB}_{1}$ ortholog, NPR-19, to modulate behavior (Oakes et al., 2017). In addition, 2-AG stimulates the NPR-19 independent release of both serotonin (5-HT) and dopamine (DA) from subsets of monoaminergic neurons to modulate locomotory behaviors through a complex monoaminergic signaling pathway involving multiple serotonin and dopamine receptors. 2-AG also inhibits locomotion in remodeled monoamine receptor mutant animals designed to measure the acute release of either 5-HT or DA, confirming the direct effects of 2-AG on monoamine release. 2-AG-dependent locomotory inhibition requires the expression of transient receptor potential vanilloid 1 (TRPV1) and TRPNlike channels in the serotonergic or dopaminergic neurons, respectively, and the acute pharmacological inhibition of the TRPV1-like channel abolishes both 2-AG-dependent 5-HT release and locomotory inhibition, suggesting the 2-AG may activate the channel directly. This study highlights the advantages of identifying and assessing both $\mathrm{CB}_{1} / \mathrm{CB}_{2}$-dependent and independent cannabinoid signaling pathways in a genetically tractable, mammalian predictive model, where cannabinoid signaling at the molecular/neuronal levels can be correlated directly with changes in behavior.

Key words: cannabinoids; dopamine; serotonin; TRP channels

\section{Significance Statement}

This study is focused on assessing $\mathrm{CB}_{1} / \mathrm{CB}_{2}$-independent cannabinoid signaling in a genetically tractable, whole-animal model where cannabinoid signaling at the molecular/neuronal levels can be correlated with behavioral change. Caenorhabditis elegans contains a cannabinoid signaling system mediated by a canonical cannabinoid receptor, NPR-19, with orthology to human $\mathrm{CB}_{1} / \mathrm{CB}_{2}$ (Oakes et al., 2017). The present study has characterized an NPR-19-independent signaling pathway that involves the cannabinoid-dependent release of both serotonin and dopamine and the expression of distinct TRP-like channels on the monoaminergic neurons. Our work should be of interest to those studying the complexities of $\mathrm{CB}_{1} / \mathrm{CB}_{2}$-independent cannabinoid signaling, the role of TRP channels in the modulation of monoaminergic signaling, and the cannabinoid-dependent modulation of behavior.

\section{Introduction}

Cannabis or marijuana alters sensory perception and has been purported to exert a wide range of recreational and medicinal

Received Sept. 22, 2018; revised Feb. 4, 2019; accepted March 8, 2019.

Author contributions: M.O., W.J.L., and R.K. designed research;M.0. and W.J.L. performed research;M.O., W.J.L., and R.K. analyzed data; R.K. wrote the paper.

This work was supported by National Institutes of Health Grant AI-072644 awarded to R.K. We thank the Caenorhabditis Genetics Center and the National Bioresources Center for null strains.

${ }^{*} M$.O. and W.J.L. contributed equally to this study.

The authors declare no competing financial interests.

Correspondence should be addressed to Richard Komuniecki at rkomuni@uoft02.utoledo.edu or richard.komuniecki@utoledo.edu. effects (Pacher et al., 2006; Grotenhermen and Müller-Vahl, 2012). Cannabis sativa contains $>60$ bioactive compounds, or phytocannabinoids (pCBs), including cannabidiol (CBD) and the hallucinogen $\Delta^{9}$-tetrahydrocannabinol (THC). These pCBs and the endogenous cannabinoids (eCBs), 2-arachidonoylglycerol (2$\mathrm{AG}$ ), and $\mathrm{N}$-arachidonoylethanolamine (AEA) differentially activate a canonical cannabinoid $(\mathrm{CB})$ signaling pathway initiated by two receptors, $\mathrm{CB}_{1}$ and $\mathrm{CB}_{2}$. $\mathrm{CB}_{1}$ and $\mathrm{CB}_{2}$ are differentially expressed and, in part, mediate a retrograde signal from postsyn-

https://doi.org/10.1523/JNEUROSCI.2371-18.2019

Copyright $\odot 2019$ the authors 
aptic neurons to inhibit neurotransmitter release. $\mathrm{CB}_{1}$ is localized primarily to presynaptic nerve terminals in the brain and CNS. $\mathrm{CB}_{2}$ is also found in the CNS, but is most robustly expressed in the immune system (Herkenham et al., 1990; Glass et al., 1997; Tsou et al., 1998; Ohno-Shosaku and Kano, 2014). CBs also modulate the release of dopamine (DA) and serotonin (5-HT), and some of the behavioral effects of CBs are mediated, either directly or indirectly, through changes in serotonergic, adrenergic, and dopaminergic signaling (Kurihara et al., 2001; Cheer et al., 2004, 2005; Sagredo et al., 2006; McLaughlin et al., 2009; Fitzgerald et al., 2012; Winters et al., 2012; Romero et al., 2013; Gantz and Bean, 2017). However, in many cases, it is unclear whether the $\mathrm{CB}$-dependent modulation of monoaminergic signaling involves $\mathrm{CB}_{1} / \mathrm{CB}_{2}$ directly or $\mathrm{CB}_{1} / \mathrm{CB}_{2}$-independent signaling pathways. For example, $\mathrm{CBs}$ also differentially activate the recently deorphanized $\mathrm{G} \alpha_{\mathrm{i} / \mathrm{o}}$-coupled receptors GPR18 and GPR55, and a range of transient receptor potential receptors, including the transient receptor potential vanilloid 1 (TRPV1) receptor (Di Marzo et al., 1998; De Petrocellis et al., 2001; Starowicz et al., 2007; Di Marzo and Maccarrone, 2008; Maccarrone et al., 2008). However, less is known about how these noncanonical CB receptors/ion channels interact with $\mathrm{CB}_{1} / \mathrm{CB}_{2}$ signaling in the modulation of $\mathrm{CB}$-dependent behaviors.

Given the complexity of the mammalian nervous system, it has been difficult to correlate studies of $\mathrm{CB}$ signaling at the molecular/neuronal levels with changes in individual behaviors. In contrast, we have focused on the genetically tractable, nematode model Caenorhabditis elegans, with the goal of examining the effects of CBs on the modulation of sensory integration and decision-making. Our recent work has demonstrated that $\mathrm{CB}$ signaling likely has ancient evolutionary origin and has identified a canonical CB signaling system in C. elegans (Oakes et al., 2017). For example, the CB-dependent modulation of nociception and feeding requires the human CB receptor ortholog NPR-19 (Oakes et al., 2017). CBs activate NPR-19 directly with affinities similar to human $\mathrm{CB}_{1}$, and $\mathrm{CB}$-dependent phenotypes can be rescued in $n p r$-19-null animals by the expression of the human $\mathrm{CB}_{1}$, confirming the proposed orthology of the two receptors (Oakes et al., 2017). CBs also extensively modulate monoaminergic signaling through NPR-19 independent pathways (Oakes et al., 2017).

Therefore, the present study is focused on characterizing the effects of CBs on monoaminergic signaling and has used the 2-AG-dependent modulation of locomotory behavior to probe NPR-19-independent CB signaling. Specifically, we have demonstrated that 2-AG inhibits forward locomotion and increases turning through NPR-19-independent pathways that involve the activation of multiple TRP channels and the endogenous release of both 5-HT and DA from subsets of monoaminergic neurons. For example, 2-AG-dependent locomotory inhibition is dramatically reduced or absent in tph-1- and cat-2-null animals that lack key enzymes required for 5-HT and DA biosynthesis, respectively and in ser-4- and dop-4-null animals that encode 5-HT and DA receptors, respectively. In contrast, 2-AG still inhibits locomotion in mod-5- or dat-1-null animals that lack reuptake transporters for either 5-HT or DA, respectively, suggesting that the primary role of 2-AG in locomotory inhibition involves the stimulation of monoamine release, not the inhibition of reuptake. Indeed, 2-AG also inhibits locomotion in remodeled monoamine receptor mutant animals designed to measure the acute release of either 5-HT or DA. This 2-AG-dependent monoamine release and locomotory inhibition requires the expression of TRPV1 and TRPN-like channels in the serotonergic or dopaminergic neu- rons, respectively, and the acute pharmacological inhibition of the $\mathrm{TRPV}_{1}$-like channel abolishes both 2-AG-dependent 5-HT release and locomotory inhibition, suggesting that the 2-AG may activate the channel directly. Together, these studies highlight the potential utility of $C$. elegans as a model to study $\mathrm{CB}_{1} / \mathrm{CB}_{2}$ independent CB signaling.

\section{Materials and Methods}

Strains and transgene construction. Strains were grown and maintained at $16^{\circ} \mathrm{C}$ and room temperature $\left(22^{\circ} \mathrm{C}\right)$ on nematode growth media (NGM) agar plates with OP50 E. coli as a food source (Brenner, 1974). All strains were purchased from the Caenorhabditis Genetics Center at the University of Minnesota (St. Paul, MN) and the National Bioresource Project at Tokyo's Women's Medical University (Tokyo, Japan). The following strains were used: N2 (Bristol), cat-1(ok411), catalog \#RB681; cat2(n4547), catalog \#MT15620; cat-4(ok342), catalog \#LC35; dat-1 (ok157), catalog \#RM2702; dop-3(ok295), catalog \#BZ873; dop-4(tm1392), catalog \#FG58; DA receptor quadruple (DA quad)-null: (dop-2(vs105) V, dop4(ok1321), dop-1(vs100), dop-3(vs106) X); mod-1(ok103), catalog \#MT9668; mod-5(n3314), catalog \#MT9772; npr-19(ok2068), catalog \#RB1668; octr-1 (ok371), catalog \#CX13079; osm-9(ky10), catalog \#CX10; ser-1(ok345), catalog \#DA1814; ser-4(ok512), catalog \#AQ866; tph1(mg280), catalog \#MT15434; trp-4(sy695), catalog \#TQ296; and 5-HT receptor quintuple (5-HT quint)-null [ser-5(tm2654);ser-4(ok512): mod1(ok103); ser-7(tm1325), ser-1(ok345)]. The ADF::tph-1 rescue strain used was CX13571 [tph-1(mg280); kySi56; kyEx4077=srh-142::nCre (95 $\mathrm{ng} / \mu \mathrm{l})$; myo-3::mCherry; $5 \mathrm{ng} / \mu \mathrm{l})]$ and was a gift from Dr. Cornelia Bargmann, The Rockefeller University, New York, NY. RNAi transgenes were generated by PCR fusion, as described in the study by Esposito et al. (2007), and coinjected with $f 25 b 3.3:: g f p$ (to $100 \mathrm{ng}$ ) as a selection marker. PCR fusions were performed as described by Hobert (2002) (Esposito et al., 2007).The unc-17 $\beta::$ ser- 4 and unc-17 $\beta::$ dop- 3 transgenes were generated by three-piece PCR fusion of the $562 \mathrm{bp}$ unc- 17 promoter ser- 4 and dop-3 cDNA, respectively, and $g f p: u n c-543^{\prime} \mathrm{UTR}$ and were injected into 5-HT quintuple- and DA quadruple-null animals, respectively.

Octanol avoidance assays. Octanol avoidance assays were performed as described in the study by and as modified by Harris et al. (2011). For all assays, L4 stage animals were picked $24 \mathrm{~h}$ before assay. To measure aversive responses to 1-octanol, the blunt end of a hair is briefly dipped in 1 -octanol and placed in front of a forward-moving worm, and the time taken to initiate backward locomotion is recorded. 2-Aminoethoxydiphenyl borate (2-APB) plates were prepared $10 \mathrm{~min}$ before assay by spreading $60 \mu \mathrm{l}$ of $10 \mu \mathrm{M} 2$-APB (in $\mathrm{H}_{2} \mathrm{O}$ ) on fresh NGM plates. During the assay, animals were first transferred to intermediate (nonseeded) plates and left for $30 \mathrm{~s}$ to remove residual bacteria. The animals were then transferred to assay plates and tested after a $10 \mathrm{~min}$ of incubation. In all assays, 20-25 worms were examined for each strain and condition, and each assay was performed at least three times. Statistical analysis was performed using mean \pm SE and Student's $t$ test.

Locomotory assay. Locomotion was assayed as described by Sawin et al. (2000). Well fed, young adult hermaphrodite animals are picked before assay and maintained on NGM plates with E. coli OP50. During the assay, seven animals were transferred to the assay plate. Motility was assessed as the number of body bends/20 s at 5 min intervals for either 15 or $20 \mathrm{~min}$, starting as soon as animals are transferred. Time 0 was recorded $\sim 20-30$ $\mathrm{s}$ after transfer to 2-AG plates. Reversal assays were performed as described in WormBook, and were assessed as the number of spontaneous reversals per $3 \mathrm{~min}$ following $10 \mathrm{~min}$ incubation in control (vehicle), 2-AG $(0.4,8$, or $320 \mu \mathrm{M}), 2$-APB $(10 \mu \mathrm{M}), 5$-HT ( $2 \mathrm{~mm})$, arachidonic acid $(320 \mu \mathrm{M}), \mathrm{DA}(5 \mathrm{mM})$, and JZL184 (320 $\mu \mathrm{M}$; Hart, 2006). For all assays, each strain was assayed at least three times with seven animals/assay and statistical analysis was performed using mean \pm SE and Student's $t$ test.

Confocal imaging and transcriptional fluorescence. To assess potential 2-AG-dependent changes in cat-2p::mCherry fluorescence, a cat-2p:: $m$ Cherry transcriptional transgene was generated by overlap PCR fusion of $1.5 \mathrm{~kb}$ of the cat-2 promoter to mCherry and was coinjected at $50 \mathrm{ng}$ with rol-6 (su1106; $50 \mathrm{ng}$ ) into wild-type (N2) animals (Hobert, 2002). Well fed L4 animals were picked $24 \mathrm{~h}$ before the assay. For assay, wild- 
type animals expressing cat-2p::mCherry were picked from plates containing OP50 and placed onto a fresh NGM plate without food to allow any residual bacteria to be removed. Animals were then picked from the transfer plates onto fresh NGM plates (10 animals/plate) containing either vehicle (water) as a control or $300 \mu \mathrm{M}$ 2-AG for $1 \mathrm{~h}$. Following treatment, animals were immobilized on $3 \%$ agarose pads with $20 \mathrm{~mm}$ sodium azide and imaged using an Olympus IX81 inverted confocal microscope. The resulting images were analyzed using ImageJ, in which each ADE and CEP neuron was isolated and $m$ Cherry fluorescence within each neuron was quantified independently using ImageJ and Microsoft Excel.

\section{Results}

Both serotonergic and dopaminergic signaling are required for 2-AG-dependent locomotory inhibition

Previously, we demonstrated that 2-AG inhibited forward locomotion in C. elegans through a pathway that did not involve the human $\mathrm{CB}_{1}$ receptor ortholog NPR-19, but instead required serotonergic signaling (Oakes et al., 2017). For example, 2-AGdependent inhibition was reduced in tph-1-null animals that lack a key enzyme required for 5-HT biosynthesis and ser-4-null animals that lack a 5-HT receptor involved in 5-HT-dependent locomotory inhibition (Law et al., 2015; Oakes et al., 2017). In contrast, inhibition was enhanced in mod-5-null animals that lack a key 5-HT reuptake transporter, suggesting that 2-AG increased endogenous 5-HT levels by stimulating 5-HT release, not inhibiting reuptake (Oakes et al., 2017).

As noted in Figure 1, the 2-AG inhibition of forward locomotion was dose dependent with an $\mathrm{IC}_{50}$ of $\sim 3 \mu \mathrm{M}$ (Fig. 1a,b). However, 2-AG did not cause complete paralysis even at high 2-AG concentrations, instead initiating a "locomotory confusion" phenotype, as described recently for the 5-HT inhibition of locomotion (Law et al., 2015). These relatively high exogenous 2-AG levels were required to overcome the relative impermeability of the nematode cuticle and do not reflect the sensitivity of the endogenous $C$. elegans $\mathrm{CB}$ signaling system. For example, the two nematode G-protein-coupled receptor (GPCRs) identified previously in the $\mathrm{CB}$-dependent modulation of aversive behavior, NPR-19 and the $\alpha_{2}$-adrenergic-like OA (octopamine) receptor OCTR-1, both exhibited affinities for 2-AG in the nM range that were similar to those reported for human $\mathrm{CB}_{1}$ and significantly below those required for the 2-AG inhibition of aversive behaviors (Oakes et al., 2017).

Since 2-AG is degraded to arachidonic acid in C. elegans by monoacylglycerol lipase (MAGL), it was also important to confirm that the effects of 2-AG did not result from its breakdown to arachidonic acid. As predicted, (1) arachidonic acid alone had no effect on the rate of forward locomotion in this assay system, in contrast to 2-AG (Fig. 1c); (2) JZL184, a MAGL inhibitor demonstrated previously to stimulate 2-AG-dependent behaviors in C. elegans, also inhibited locomotion, presumably by increasing endogenous 2-AG levels (Fig. 1c; Oakes et al., 2017); and (3) the effects of exogenous 2-AG were enhanced in the presence of JZL184 (Fig. 1c). Importantly, this JZL184-dependent inhibition was also NPR-19 independent and SER-4 dependent, supporting a role for endogenous 2-AG signaling in locomotory modulation (Fig. 1c). To confirm this $n p r-19$ result, we also examined locomotion in wild-type animals expressing an $n p r-19$ RNAi driven by an $n p r-19$ promoter. The effectiveness of this $n p r-19$ RNAi construct has been validated previously and abolishes the 2-AGdependent inhibition of aversive responses, mimicking the npr19-null animals (Oakes et al., 2017). As predicted, the expression of the npr-19 RNAi had no effect on either the 2-AG- or JZL184dependent inhibition of locomotion (Fig. 1c).
2-AG-dependent locomotory inhibition also required the release of DA, in addition to 5-HT (Fig. 1d,e; Oakes et al., 2017). For example, 2-AG-dependent inhibition was absent in cat-2-null animals that lack tyrosine hydroxylase, a key enzyme involved in DA biosynthesis (Fig. 1d). DA levels are dramatically reduced in cat-2-null animals (Sanyal et al., 2004). Importantly, 2-AGdependent inhibition was still present in dat-1-null animals that a lack key DA reuptake transporter, suggesting that the primary role of 2-AG in locomotory inhibition involves the stimulation DA release, not the inhibition of reuptake, as also reported for 5-HT (Fig. 1d,e; Oakes et al., 2017). Similarly, 2-AG-dependent inhibition was absent in dop-2; dop-4 dop-1 dop-3 DA receptor quadruple-null animals (DA quads) that lack key DA receptors and in dop-4-null animals that lack a $\mathrm{G} \alpha_{\mathrm{s}}$-coupled DA receptor (Fig. 1e). Additionally, RNAi knockdown of DOP-4 (a $\alpha_{\mathrm{s}}$ coupled DA receptor) in wild-type animals mimicked the dop-4null phenotype (Fig. 1e). In contrast, dop-3-null animals lacking a $\mathrm{G} \alpha_{\mathrm{o}}$-coupled DA receptor were hypersensitive to 2-AG inhibition (Fig. 1e), highlighting the antagonistic interaction between DOP-3 and DOP-4 signaling described previously for the DA modulation of aversive behaviors (Ezak and Ferkey, 2010; Ezcurra et al., 2011).

Interestingly, the temporal pattern of 2-AG modulation differed significantly in the 5-HT- and DA-deficient signaling mutants. For example, in mutants with disrupted serotonergic signaling, tph-1, ser-4, and 5-HT receptor quintuple-null animals (5-HT quints), 2-AG-dependent inhibition was initially delayed, but eventually these mutant animals began to slow (Fig. 1d). Importantly, RNAi knockdown of SER-4 in the AIB interneurons of wild-type animals mimicked ser-4-null animals, and 2-AG sensitivity was restored to 5-HT quints following neuron-specific rescue of SER-4 in the AIB interneurons (Fig. 1d). In contrast, in mutants with disrupted DA signaling, 2-AG never inhibited locomotion and, in fact, 2 -AG rapidly $(<30 \mathrm{~s})$ and significantly $(>25 \%)$ stimulated locomotion in these mutants, compared with the same mutants in the absence of 2-AG (Fig. 1e).

As expected, 2-AG-dependent inhibition also was markedly reduced in cat-1- and cat-4-null animals with compromised DA and 5-HT signaling (Fig. 1f). cat-1 encodes a synaptic vesicular monoamine transporter and cat-4 an ortholog of human GTP cyclohydrolase 1 that contains reduced levels of both 5-HT and DA (Sulston et al., 1975; Desai et al., 1988; Nurrish et al., 1999). Interestingly, 2-AG did not initially stimulate locomotion in the cat-4-null animals, as observed for cat-2 or DA quad mutants with disrupted DA signaling, suggesting that serotonergic signaling might be involved in this CB-dependent stimulation. Interestingly, 2-AG inhibition could be rescued in the cat-4-null animals by preincubation in either 5-HT or DA (Fig. $1 f$ ), suggesting that the overstimulation of either 5-HT or DA signaling compensated for reduced levels of the other. Similar compensatory responses in both C. elegans monoaminergic and peptidergic signaling have been reported previously, where the overexpression of one gene compensates for the absence of another.

2-AG also stimulated reversals, in addition to inhibiting forward locomotion (Fig. 2a). This 2-AG-dependent stimulation did not require npr-19 or cat-2, but was absent in tph-1-, mod-1-, and ser-1-null animals (Fig. 2a). mod-1 and ser-1 encode a 5-HTgated $\mathrm{Cl}^{-}$channel and a $\mathrm{G}_{\mathrm{q}}$-coupled 5-HT receptor, respectively, that have previously been implicated in modulation of reversal behavior associated with nociception (Harris et al., 2009, 2011). Together, these data suggest that 2-AG stimulates the release of both 5-HT and DA to activate a complex monoaminergic signaling network to inhibit locomotion and increase turning. 
a

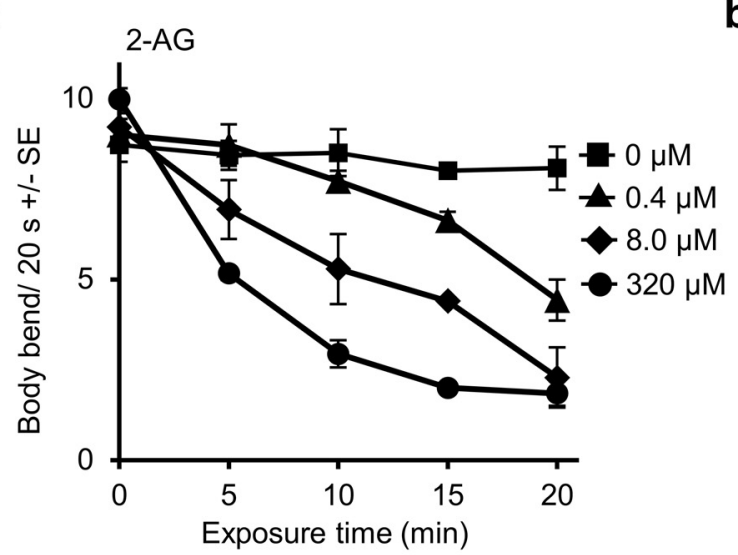

C

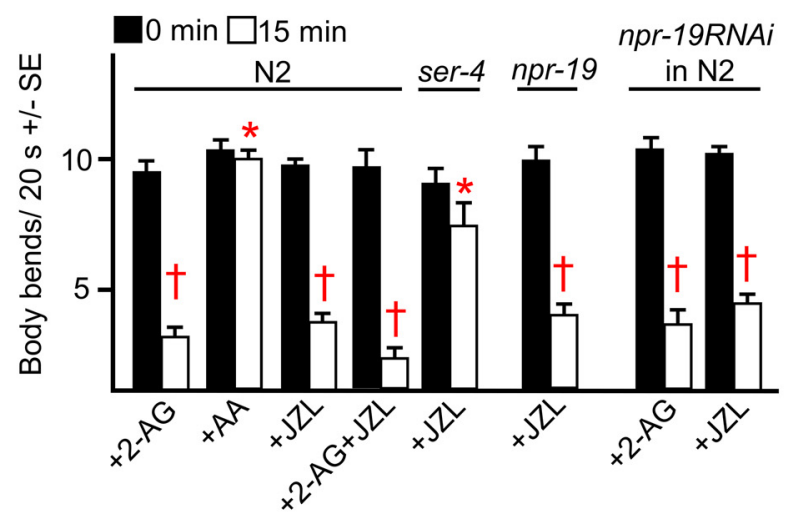

e

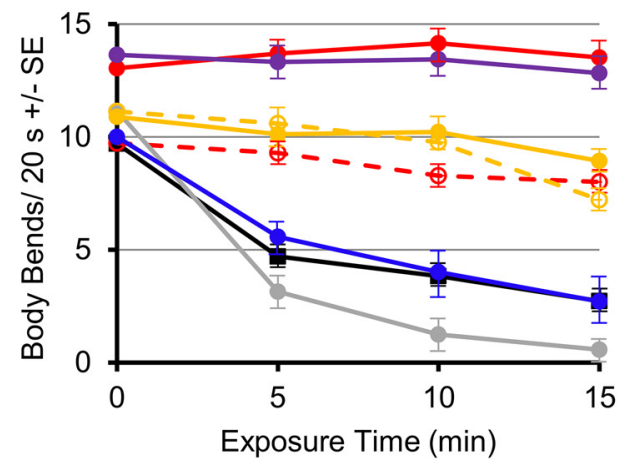

b

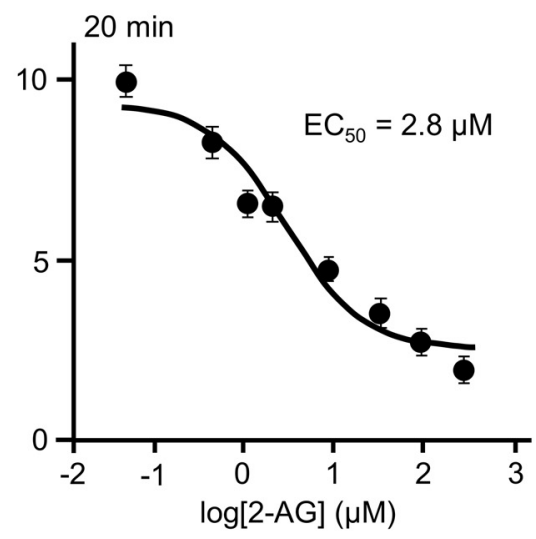

d

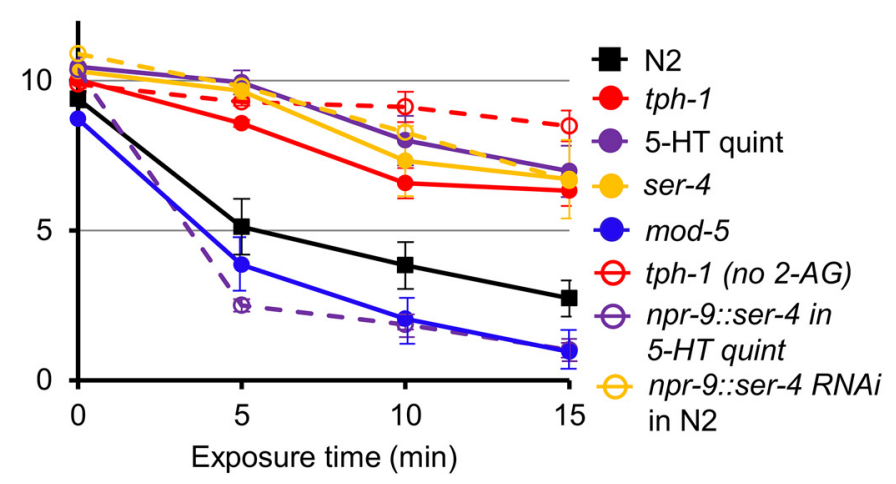

f

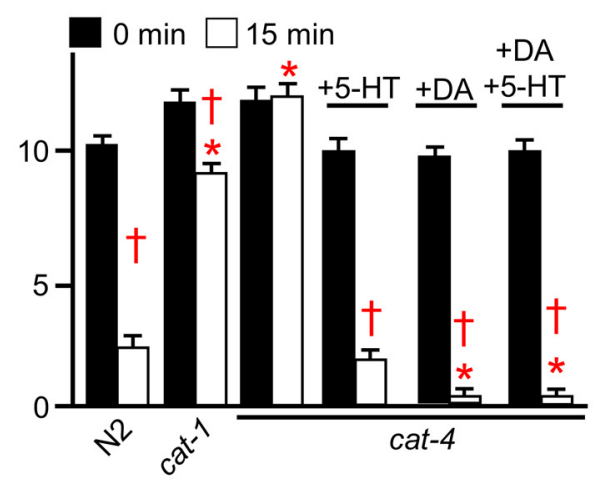

Figure 1. 2-AG-dependent locomotory inhibition requires both serotonergic and dopaminergic signaling. Wild-type and mutant animals were incubated in 2-AG, and locomotion was assayed as body bends/20 s, as described in Materials and Methods. a, 2-AG-dependent locomotory inhibition in wild-type (N2) animals. $\boldsymbol{b}, 2$, AG dose-response curve for wild-type animals. c, JZL184 (JZL) inhibits locomotion in wild-type animals. $\boldsymbol{d}, \boldsymbol{e}, 2$-AG-dependent locomotory inhibition requires both serotonergic and dopaminergic signaling. $\boldsymbol{f}$, Exogenous 5 -HT or DA restores 2-AG-dependent locomotory inhibition in 5-HT- and DA-deficient cat-4-null animals. The mutant animals used were as follows: cat-1(ok411), cat-2(n4547), cat-4(ok342), dat-1(ok157), dop-3(ok295), dop4(tm1392), DA receptor quadruple (DA quad)-null [dop-2(vs105) V, dop-4(ok1321) dop-1(vs100), dop-3(vs106) X], mod-5(n3314), npr-19(ok2068), ser-4(ok512), tph-1(mg280), and 5-HT quint-null [ser-5 (tm2654);ser-4(ok512), mod-1(ok103);ser-7(tm1325), and ser-1(ok345)]. The npr-19 RNAi strain are wild-type animals expressing an npr-19::npr-19 RNAi transgene driven by the native $n p r-19$ promoter. ${ }^{*}$ Indicates significantly different from wild-type animals at $15 \mathrm{~min}$; $†$ indicates significantly different from the same animals at time 0 ( $p \leq 0.05$ ). Data are presented as the mean \pm SE $(n)$ and were analyzed by two-tailed Student's $t$ test using GraphPad software.

2-AG stimulates the release of DA from subsets of DA neurons

To measure the acute, 2-AG-dependent release of DA directly, we created mutant, transgenic animals expressing the $\mathrm{G} \alpha_{\mathrm{o}}$-coupled DA receptor DOP-3 directly in the cholinergic motor neurons of DA quad mutants, on the assumption that any 2-AG-dependent DA release would activate DOP-3 on the motor neurons, inhibit acetylcholine release onto the muscle, and inhibit locomotion (Fig. 3a). We used a similar approach previously to measure acute 5-HT release (Oakes et al., 2017). DA or 2-AG had no effect on forward locomotion in the DA quad mutants, but both rapidly inhibited locomotion after the expression of the inhibitory DOP-3 in the motor neurons of the remodeled quad mutants (Fig. 3b). Together, these data demonstrate that the 2-AG-dependent inhibition of forward locomotion requires the release of DA.

Identification of the neurons involved in 2-AG-dependent 5-HT and DA release

To identify the monoaminergic neurons involved in 2-AGdependent locomotory inhibition, we used a combination of se- 
lective RNAi knockdown/rescue in the serotonergic neurons, where selective promoters were available. Indeed, the selective expression of $t p h-1$ in the ADF neurons rescued 2-AG-dependent locomotory inhibition in tph-1-null animals (Fig. 4a). In contrast, but in agreement with the ADF-selective rescue, ADFselective RNAi knockdown of tph-1 in wild-type animals abolished 2-AGdependent inhibition (Fig. 4a). Together, these data suggest that $2-A G$ stimulates the release of 5-HT from serotonergic $\mathrm{ADF}$ neurons to mediate CB-dependent locomotory inhibition.

To identify the dopaminergic neurons involved in the 2-AG-dependent locomotory inhibition, we measured CB-dependent increases in cat-2::gfp fluorescence, on the assumption that, following 2-AG-dependent DA release, DA biosynthesis would be upregulated to replenish DA stores. As predicted, cat-2 expression was observed in the two ADE and four CEP neurons in the anterior of the transgenic animals (Fig. 4b), confirming the predicted cat-2 expression pattern (Suo et al., 2003). 2-AG robustly increased cat-2::mCherry fluorescence in the ADEs, but not the CEPs, suggesting that 2-AG may stimulate DA release selectively from the ADEs at a minimum (Fig. 4c).

TRP channels are required for the 2-AG-dependent inhibition of locomotion

To identify the pathways involved in 2-AG-dependent locomotory inhibition and monoamine release, we screened for reduced 2-AG-dependent inhibition in a range of signaling mutants. Using this approach, we identified a number of TRP channel mutants that were resistant to 2-AG-dependent inhibition, including $\operatorname{trp}-4$ that encodes the pore-forming subunit of a mechanosensitive TRPN [NOMPC (mechanoreceptor potential channel)] channel that localizes to the cilia of the dopaminergic neurons and osm-9 that encodes a TRPV ${ }_{1}$-like subunit expressed in many sensory neurons (Fig. 5a). Interestingly, the temporal pattern of slowing in the trp-4 and osm-9 mutants mimicked those of dopamine- and serotonin-deficient animals, respectively (Fig. $5 a$ ). Many CBs activate mammalian TRP channels with affinities in the low-nanomolar range, although little is known about the physiological role of these channels in CB-dependent behavioral modulation (Di Marzo et al., 1998; De Petrocellis et al., 2001; Di Marzo and Maccarrone, 2008; Maccarrone et al., 2008; De Petrocellis and Di Marzo, 2010).

2-AG stimulated locomotion in the trp-4-null animals, a phenotype also observed in animals deficient in dopaminergic signaling, and trp-4 RNAi knockdown in the dopaminergic neurons mimicked the trp-4-null phenotype, suggesting that TRP-4 functioned in the dopaminergic neurons to stimulate DA release (Fig. $5 b, c)$. In contrast, as mentioned previously, the temporal pattern of slowing in the osm-9 mutants mimicked that observed in animals with compromised serotonergic signaling, as outlined above, and osm-9 RNAi knockdown in the serotonergic neurons, using the tph-1 promoter mimicked the osm-9-null phenotype, suggesting that osm-9 functioned directly in the serotonergic neurons (Fig. 5c). OSM-9 and OCR-2 form a heteromeric channel in many sensory neurons, and osm-9- or ocr-2-null animals do not accumulate significant 5-HT in the two serotonergic ADF sensory neurons, identified above in the 2-AG-dependent locomotory inhibition (Zhang et al., 2004). The activation of an

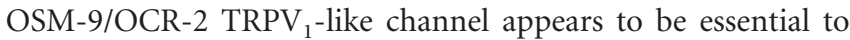
activate ADF tph-1 transcription (Zhang et al., 2004; Sokolchik et al., 2005; Sze, 2007). This observation suggested that the lack of 2-AG inhibition in osm-9 mutant animals could result from the absence of 5-HT in the ADFs and not a failure of 2-AG to activate an ADF TRPV ${ }_{1}$-like channel to stimulate 5-HT release. Unfortunately, ocr-2-null animals could not be assessed in this assay, as ocr-2-null animals slowed significantly in the absence of 2-AG (Colbert et al., 1997).

Therefore, to confirm a role for the acute activation of an OSM-9/TRPV ${ }_{1}$-like channel in 2-AG-dependent inhibition, we incubated animals in 2-APB, which at low concentrations inhibits TRPV channels in other systems (Xu et al., 2005; Togashi et al., 2008). As anticipated, acute exposure to 2-APB had no effect on locomotion in wild-type animals but, as predicted, dramatically decreased aversive responses to dilute 1-octanol to levels observed in osm-9-null animals (Fig. 6a,b). Aversive responses to dilute 1-octanol require the activation of a heteromeric OSM-9/ OCR-2 $\mathrm{TRPV}_{1}$-like channel in the two ASH sensory neurons,

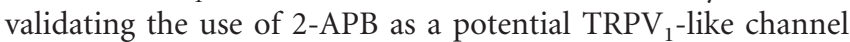
inhibitor in these studies (Colbert et al., 1997; Tobin et al., 2002). 2-ABP inhibited 2-AG-dependent locomotory inhibition in wild-type animals and in the remodeled 5-HT quints designed to measure acute 5-HT release, but, as predicted, had no effect on 5-HT-dependent locomotory inhibition in these same remodeled mutant animals, supporting our hypothesis that the activation of a TRPV $\mathrm{T}_{1}$-like channel in the serotonergic neurons was required for 5 -HT release (Fig. $6 b$ ). In contrast, 2-APB had no effect on either DA- or 2-AG-dependent locomotory inhibition in remodeled DA quad mutants designed to measure acute DA release (Fig. $6 c$ ). Whether the TRP-4 channel is insensitive to 
a

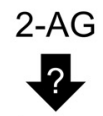

DA release from dopaminergic neurons

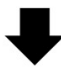

Activation of DOP-3 in the cholinergic motorneurons of DA receptor quad null animals

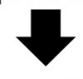

Decreased ACh release onto body wall muscle

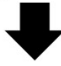

Locomotory inhibition b

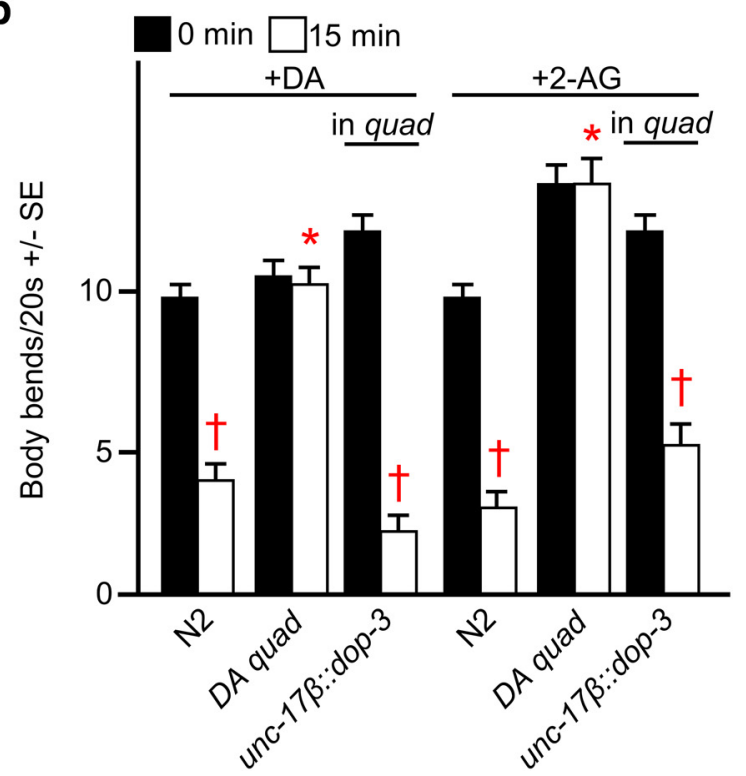

Figure 3. 2-AG inhibits locomotion in C. elegans quadruple dopamine receptor mutants remodeled to detect acute dopamine release. Wild-type, mutant, and remodeled animals were incubated in 2-AG, and locomotion was assayed as body bends/20 s, as described in Materials and Methods. $\boldsymbol{a}$, To detect acute 2-AG-stimulated DA release, the $G \alpha_{0}$-coupled $D_{2}$-like receptor DOP-3 was expressed in the cholinergic motor neurons of DA receptor quadruple-null (DA quad) animals under the assumption that any 2-AG-dependent DA release would activate DOP-3 on the motor neurons, inhibit acetylcholine release, and inhibit locomotion. $\boldsymbol{b}$, DA or 2-AG-dependent locomotory inhibition was restored in DA quad animals designed to measure acute DA release. The unc-17 $\beta$ promoter drives expression in the cholinergic motor neurons. ${ }^{*}$ Indicates significantly different from wild-type animals at 15 min; + indicates significantly different from the same animals at time 0 ( $p \leq 0.05$ ). Data are presented as the mean \pm SE $(n)$ and were analyzed by two-tailed Student's $t$ test using GraphPad software.

a

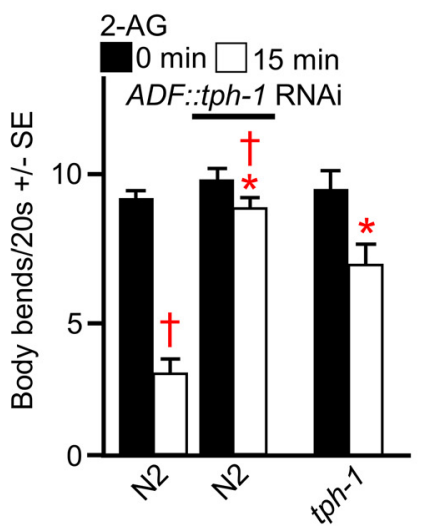

b

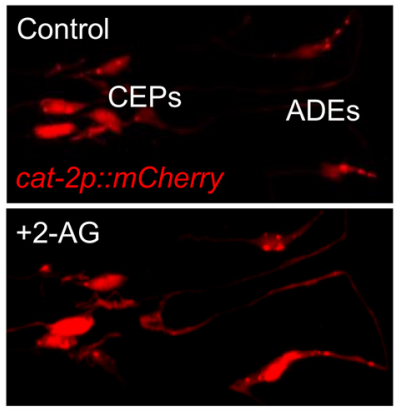

C

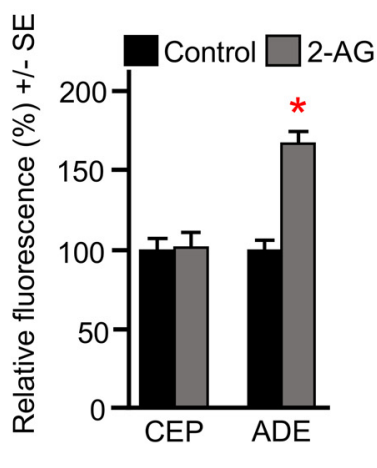

Figure 4. Identification of the monoaminergic neurons involved in 2-AG-dependent locomotory inhibition. $\boldsymbol{a}$, ADF-selective RNAi knockdown of tph-1 in wild-type (N2) animals abolished 2-AG-dependent locomotory inhibition and ADF-selective expression of tph-1 restored 2-AG sensitivity of tph-1 ( $m g 280$ )-null animals. $\boldsymbol{b}$, Fluorescence from a cat-2p:: $m$ Cherry transgene confirms $m$ Cherry expression in the dopaminergic CEPs and ADEs.c, cat-2p:::mCherry fluorescence in the dopaminergic CEP and ADE neurons was analyzed after 2-AG incubation, as described in Materials and Methods. Images were captured using an Olympus IX81 confocal microscope and analyzed using ImageJ. * Indicates significantly different from wild-type animals at 15 min; $†$ indicates significantly different from the same animals at time 0 ( $p \leq 0.05)$. Data are presented as the mean \pm SE $(n)$ and analyzed by two-tailed Student's $t$ test using GraphPad software.

2- $\mathrm{APB}$ or requires higher $2-\mathrm{APB}$ concentrations for inhibition is unclear. Cilia of the dopaminergic neurons, where TRP-4 is expressed, are embedded directly in the cuticle, potentially making them less responsive to perturbations in the external environment, in contrast to dendrites from sensory neurons found in the amphids that are directly exposed to the external environment (Inglis et al., 2007). Unfortunately, higher 2-APB concentrations (10-fold) inhibited locomotion in wild-type animals. Together, observations support the hypothesis that 2-AG-dependent inhibition requires the activation of TRP channels on the monoaminergic neurons and monoamine release to inhibit forward locomotion and increase turning.

\section{Discussion}

Cannabis alters sensory perception and has been purported to be useful for the treatment of a range of disorders, including anxiety, epilepsy, nausea, loss of appetite, and pain management (Gross et al., 2004; Svendsen et al., 2004; Wissel et al., 2006; Haney et al., 2007; Bedse et al., 2017). Although initial reports suggested that nematodes lacked canonical CB receptors, our recent work demonstrates that C. elegans contains an endogenous CB signaling system mediated by a CB receptor, NPR-19 (Oakes et al., 2017). NPR-19 responds directly to the endogenous CBs 2-AG and AEA with affinities similar to human $\mathrm{CB}_{1}$ (Lehtonen et al., 2011; Oakes 
a

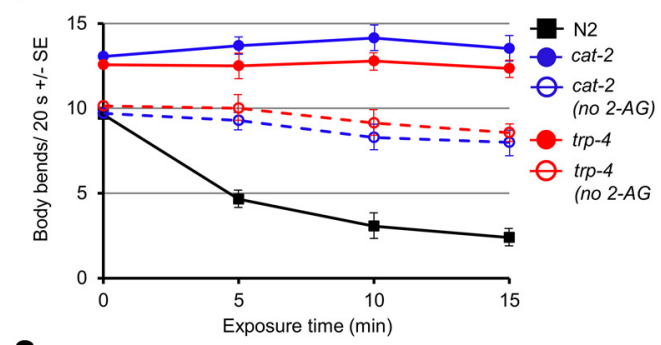

C

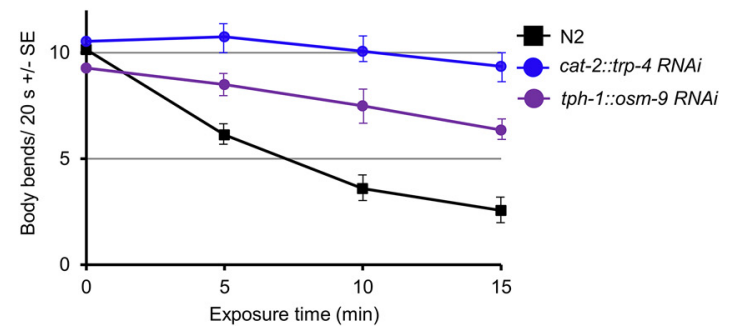

b

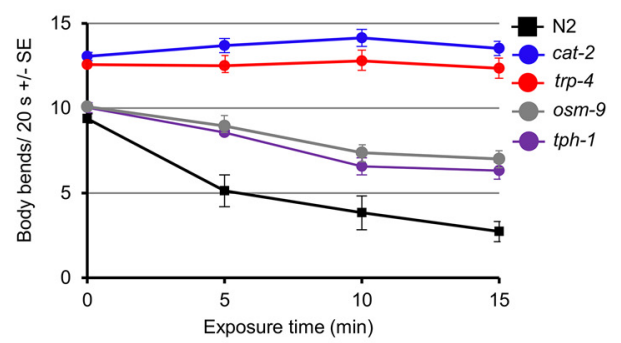

Figure 5. 2-AG-dependent locomotory inhibition requires the TRP-like channels OSM-9 and TRP-4 in the serotonergic and dopaminergic neurons, respectively. Animals were incubated in 2-AG and locomotion was assayed as body bends/20 s as described in Materials and Methods. $a, 05 m-9$ (ky10)- and trp-4 (sy695)-null animals are resistant to 2-AG-dependent locomotory inhibition and the temporal patterns of resistance to 2-AG-dependent locomotory inhibition in osm-9- and trp-4-null animals mimics similar patterns in tph-1 (mg280)- and cat-2 (n4547)-null animals, respectively. $\boldsymbol{b}$, Locomotion in trp-4- and cat-2-null animals is stimulated in the presence of 2-AG. c, Selective osm-9 and trp-4 RNAi knockdown in the serotonergic and dopaminergic neurons of wild-type animals, driven by the tph-1 and cat-2 promoters, respectively, abolishes 2-AG-dependent locomotory inhibition. Data are presented as the mean \pm SE $(n)$ and analyzed by two-tailed Student's $t$ test using GraphPad software.

et al., 2017). As demonstrated in this and our previous study, CBs cause a "dazed and confused" phenotype, inhibiting aversive behavior, feeding, and locomotion, and increasing turning. CBs also modulate additional processes in C. elegans, including neuronal migration, dauer formation, and cholesterol metabolism (Lucanic et al., 2011; Reis Rodrigues et al., 2016; Galles et al., 2018). The effects of CBs on aversive behavior, feeding, and axon regeneration require NPR-19 (Pastuhov et al., 2016; Oakes et al., 2017). In contrast, $2-A G$ signals through NPR-19-independent pathways to inhibit forward locomotion and increase turning. This NPR-19-independent signaling requires multiple TRP channels and the release of both 5-HT and DA from subsets of monoaminergic neurons.

\section{TRP channels are essential for 2-AG-dependent 5-HT and DA release}

2-AG-dependent locomotory inhibition and monoamine release are also absent in osm-9- and trp-4-null animals that lack a $\mathrm{TRPV}_{1}$-like channel subunit expressed in the ADFs and the poreforming subunit of a mechanosensitive TRPN (NOMPC) channel expressed in the dopaminergic neurons, respectively. 2-AG actually stimulates locomotion in the trp-4-null animals, a phenotype also observed in animals deficient in dopaminergic signaling and trp-4 knockdown in the dopaminergic neurons mimicked the trp-4-null phenotype, suggesting that TRP-4 functions directly in the dopaminergic neurons to stimulate DA release. Functional correlations between TRP-4 signaling in the dopaminergic neurons and DA-dependent locomotory behaviors have been demonstrated previously. For example, trp-4-null animals are deficient in the basal slowing behavior that is dependent on DA release (Kindt et al., 2007). In contrast, the temporal pattern of slowing in the TRPV1-like mutants mimics that observed in animals with compromised serotonergic signaling, and osm-9 knockdown in the serotonergic neurons mimics the osm9-null phenotype, suggesting that osm-9 functions in the seroto- nergic neurons. Importantly, 2-APB that at low concentrations inhibits TRPV channels in both nematodes and mammals also acutely inhibits 2-AG-dependent locomotory inhibition in both wild-type animals and remodeled 5-HT receptor mutant animals designed to measure 5-HT release. Together, these data suggest that 2-AG may activate multiple TRP channels in C. elegans to modulate the release of monoamines from distinct subsets of serotonergic and dopaminergic neurons, as also observed in mammals (Fig. 7; Sagredo et al., 2006: De Luca et al., 2014).

\section{Similarities between CB signaling in nematodes and mammals}

Our recent work has identified many similarities between $\mathrm{CB}$ signaling in mammals and nematodes. Indeed, the utility of $C$. elegans as a translational tool for understanding basic processes and drug action in the mammalian nervous system is well documented (Engleman et al., 2016). Although C. elegans contains a compact nervous system (only 302 neurons and $\sim 7000$ synapses), it still exhibits complex behaviors modulated by serotonergic, dopaminergic, adrenergic (octopaminergic), and opioid signaling that are mediated by receptors with clear orthology to their mammalian counterparts (Allen et al., 2011; Law et al., 2015; Mills et al., 2016; Oakes et al., 2017). Similarly, the noradrenergic/ octopaminergic inhibition of pain/aversive responses is also similar in mammals and nematodes, with $\alpha_{2}$-adrenergic receptors inhibiting primary nociceptors and $\alpha_{1}$-like adrenergic receptors stimulating the release of an array of inhibitory neuropeptides (Pertovaara, 2006; Komuniecki et al., 2012; Mills et al., 2012).

Aspects of CB signaling are conserved between mammals and nematodes, and both systems contain an $\mathrm{eCB}$ signaling system mediated by canonical CB receptors. For example, mammalian and nematode systems do the following: (1) synthesize identical $\mathrm{CBs}$, 2-AG, and AEA, and express orthologous receptors $\mathrm{CB}_{1} /$ $\mathrm{CB}_{2}$ in mammals and NPR-19 in nematodes (Lehtonen et al., 
a

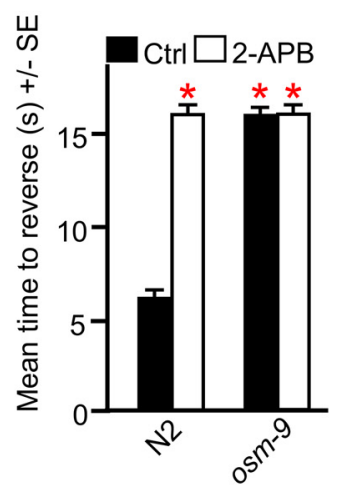

C

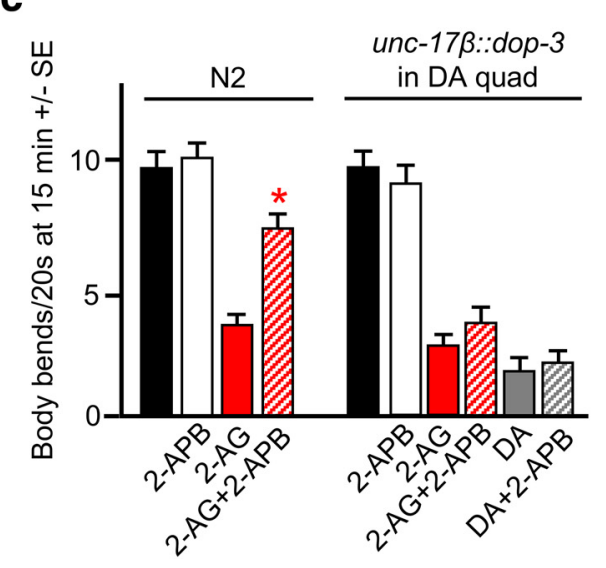

Figure 6. The TRPV channel blocker 2-APB abolishes 2-AG-dependent locomotory inhibition in wild-type and remodeled C. elegans designed to detect acute $5-\mathrm{HT}$ release. Wild-type and mutant animals were incubated in 2-AG and/or 2-APB, and locomotory and 1-octanol avoidance assays were performed as described in Materials and Methods. $\boldsymbol{a}, 2$-APB inhibits basal aversive responses to $100 \%$ 1-octanol and mimics the octanol-resistant phenotype of osm-9-null animals. b, 2-APB has no effect on locomotion in wild-type animals, but abolishes 2-AG-dependent locomotory inhibition in remodeled C. elegans designed to detect acute 5-HT release. C, 2-APB has no effect on 2-AG-dependent locomotory inhibition in remodeled C. elegans designed to detect acute DA release. The unc- $17 \beta$ promoter drives expression in the cholinergic motor neurons. * Indicates significantly different from wild-type animals at $15 \mathrm{~min}$; $†$ indicates statistically significant from the same animals at time $0(p \leq 0.05)$. Data are presented as the mean $\pm S E(n)$ and analyzed by two-tailed Student's $t$ test using GraphPad software.

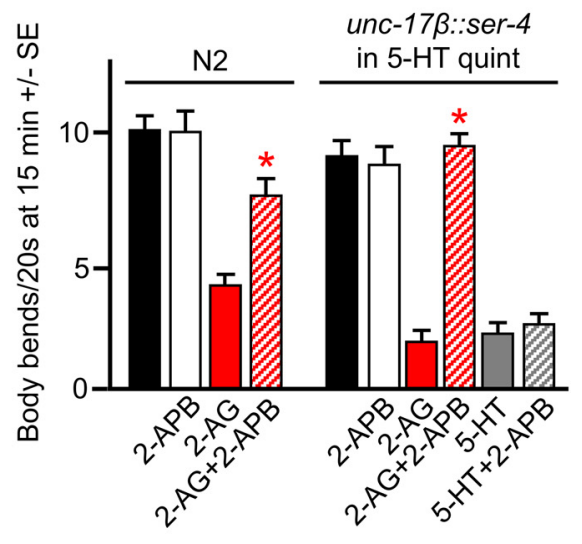

2011; Oakes et al., 2017); (2) degrade CBs through similar pathways mediated by MAGL for 2-AG and fatty acid amide hydroxylase (FAAH) for AEA hydrolysis, and both nematode-degradative enzymes Y97E10AL and FAAH-1 appear to be inhibited by antagonists specific for their mammalian counterparts (Oakes et al., 2017); and (3) exhibit significant $\mathrm{CB}_{1} / \mathrm{CB}_{2}$ or NPR-19-independent CB signaling, mediated by additional GPCRs and TRP channels. For example, in mammals CBs also differentially activate the mammalian GPCRs, GPR18, and GPR55 (Begg et al., 2005; Kohno et al., 2006; Overton et al., 2006; Ryberg et al., 2007; Lauckner et al., 2008; McHugh et al., 2012; MartínezPinilla et al., 2014). However, CB/GPCR interactions are complex and often antagonistic. For example, 2-AG, AEA, and THC function as agonists for GPR55, while CBD functions as an antagonist (Ryberg et al., 2007). CBs also activate at least five different TRP channels with affinities in the nanomolar range, including TRPV1 and a range on TRP channels in $C$. elegans (De Petrocellis and Di Marzo, 2010; Zygmunt et al., 2013). CB/TRP channel interactions are also complex. For example, AEA inhibits nociception by activating $\mathrm{CB}_{1}$ and at higher concentrations TRPV1 (Morisset et al., 2001; Iskedjian et al., 2007; Horvath et al., 2008; Clapper et al., 2010; Zygmunt et al., 2013). In contrast, $N$-arachidonoyl5-HT, an eCB that functions as a dual blocker of FAAH and the TRPV1 channel, induces anxiolytic effects by stimulating $\mathrm{CB}_{1}$ and inhibiting TRPV1, highlighting the potentially complex interactions between these different CB-dependent signaling pathways (Gobira et al., 2017).

CBs also modulate the release of both 5-HT and DA in both nematodes and mammals, and some of the behavioral effects of CBs are mediated, either directly or indirectly, through the complex modulation of serotonergic and dopaminergic signaling. For example, CBs extensively modulate serotonergic signaling in mammals. However, the behavioral consequences of CBdependent modulation of serotonergic signaling have not been fully characterized. In general, CBs modulate the synthesis, release, and turnover of 5-HT, inhibit 5-HT reuptake and modulate the efficacy of 5-HT receptors, although many of these observations are dependent on the neurons and CBs involved. For example, CBs inhibit 5-HT reuptake in rats and THC increases 5-HT levels in the rat prefrontal cortex (Steffens and Feuerstein, 2004; Sagredo et al., 2006). In addition, the pCB $\Delta^{9}$-tetrahydrocannabivarin appears to act through $5-\mathrm{HT}_{1 \mathrm{~A}}$ receptors to increase the efficacy, but not the $\mathrm{EC}_{50}$ of the $5-\mathrm{HT}_{1 \mathrm{~A}}$ agonist $8-\mathrm{OH}-\mathrm{DPAT}$ (Cascio et al., 2015). In contrast, the inhibition or genetic knockdown of $\mathrm{CB}_{1}$ increases endogenous 5-HT levels, suggesting that eCBs inhibit 5-HT release and $\mathrm{CB}_{1}$ knockdown in mice increases $5-\mathrm{HT}_{1 \mathrm{~A}}$ and $5-\mathrm{HT}_{2 \mathrm{~A}}$ receptor efficacy, but decreases serotonergic neuronal activation (Darmani et al., 2003; Mato et al., 2007; Aso
Figure 7. Model of 2-AG-dependent modulation of locomotory behavior. 2-AG stimulates the release of 5-HT from the serotonergic ADF neurons and DA from the dopaminergic ADE neurons to stimulate spontaneous reversal and inhibit forward locomotion through a pathway requiring the TRPV-like channel subunit OSM- 9 and the TRPN-like channel subunit TRP-4, respectively. SER-1, $\mathrm{G} \alpha_{\mathrm{q}}$ coupled 5-HT receptor; SER-4, $\mathrm{G} \alpha_{0}$-coupled 5-HT receptor; MOD-1, 5-HT-gated chloride channel. 
et al., 2009). In C. elegans, CBs do not appear to activate 5-HT receptors directly, increase their efficacy for 5-HT, or block 5-HT reuptake, but instead stimulate the release of endogenous 5 -HT via a mechanism requiring $\mathrm{TRPV}_{1}$-like channel activation (Oakes et al., 2017).

Similarly, 2-AG and AEA increase the firing rate of dopaminergic neurons in mammals and stimulate DA release directly by activating TRP channels expressed on dopaminergic neurons and indirectly by inhibiting GABA release upstream of dopaminergic neurons via $\mathrm{CB}_{1}$-dependent activation (Cheer et al., 2005; Starowicz et al., 2007; Zygmunt et al., 2013; De Luca et al., 2014; Wang et al., 2015). In C. elegans, CB-dependent DA release is NPR-19 independent and requires a TRPN-like channel expressed on the dopaminergic neurons, although a role for CBs in modulating inputs into the $C$. elegans dopaminergic neurons remains to be examined. Given the complexity of the mammalian nervous system and the range of potential CB receptor ligands, generalizations about specific signaling pathways are complicated and the relative significance of $\mathrm{CB}_{1} / \mathrm{CB}_{2}$-dependent and $\mathrm{CB}_{1} / \mathrm{CB}_{2}$ independent signaling in behavioral modulation in mammals is not fully understood. The present study highlights similarities between $\mathrm{CB}$ signaling in mammals and nematodes and the potential benefit for the additional study in C. elegans, especially the examination of pCBs. For example, CBD appears to be involved in many of the proposed medicinal benefits of CB signaling, suggesting that the study of CBD signaling in C. elegans is warranted (Pertwee, 2005). In addition, the effects of CBs are rapid in $C$. elegans, and TRP channel activation is essential for the release of both 5-HT and DA, suggesting that CBs might begin to alter sensory processing almost immediately upon exposure. Indeed, CBs gate at least five distinct TRP channels in mammals, suggesting that the relationship between CB-dependent TRP channel activation and monoaminergic signaling in mammals might benefit from additional examination (De Petrocellis et al., 2001; Bandell et al., 2004; McIntosh et al., 2007). Finally, much remains to be learned about how eCB and pCB signaling interact and how ligands with similar affinity for canonical CB receptors initiate such dramatic differences in downstream signaling and ultimately behavior. C. elegans may prove to be a useful model to decipher these subtle interactions operating in more complex nervous systems.

\section{References}

Allen AT, Maher KN, Wani KA, Betts KE, Chase DL (2011) Coexpressed D1- and D2-like dopamine receptors antagonistically modulate acetylcholine release in Caenorhabditis elegans. Genetics 188:579-590.

Aso E, Renoir T, Mengod G, Ledent C, Hamon M, Maldonado R, Lanfumey L, Valverde O (2009) Lack of CB1 receptor activity impairs serotonergic negative feedback. J Neurochem 109:935-944.

Bandell M, Story GM, Hwang SW, Viswanath V, Eid SR, Petrus MJ, Earley TJ, Patapoutian A (2004) Noxious cold ion channel TRPA1 is activated by pungent compounds and bradykinin. Neuron 41:849-857.

Bedse G, Hartley ND, Neale E, Gaulden AD, Patrick TA, Kingsley PJ, Uddin MJ, Plath N, Marnett LJ, Patel S (2017) Functional redundancy between canonical endocannabinoid signaling systems in the modulation of anxiety. Biol Psychiatry 82:488-499.

Begg M, Pacher P, Bátkai S, Osei-Hyiaman D, Offertáler L, Mo FM, Liu J, Kunos G (2005) Evidence for novel cannabinoid receptors. Pharmacol Ther 106:133-145.

Brenner S (1974) The genetics of Caenorhabditis elegans. Genetics 77:7194.

Cascio MG, Zamberletti E, Marini P, Parolaro D, Pertwee RG (2015) The phytocannabinoid, Delta(9)-tetrahydrocannabivarin, can act through 5-HT1A receptors to produce antipsychotic effects. Br J Pharmacol 172: $1305-1318$.

Cheer JF, Wassum KM, Heien ML, Phillips PE, Wightman RM (2004) Can- nabinoids enhance subsecond dopamine release in the nucleus accumbens of awake rats. J Neurosci 24:4393-4400.

Cheer JF, Heien ML, Garris PA, Carelli RM, Wightman RM (2005) Simultaneous dopamine and single-unit recordings reveal accumbens GABAergic responses: implications for intracranial self-stimulation. Proc Natl Acad Sci U S A 102:19150-19155.

Clapper JR, Moreno-Sanz G, Russo R, Guijarro A, Vacondio F, Duranti A, Tontini A, Sanchini S, Sciolino NR, Spradley JM, Hohmann AG, Calignano A, Mor M, Tarzia G, Piomelli D (2010) Anandamide suppresses pain initiation through a peripheral endocannabinoid mechanism. Nat Neurosci 13:1265-1270.

Colbert HA, Smith TL, Bargmann CI (1997) OSM-9, a novel protein with structural similarity to channels, is required for olfaction, mechanosensation, and olfactory adaptation in Caenorhabditis elegans. J Neurosci 17:8259-8269.

Darmani NA, Janoyan JJ, Kumar N, Crim JL (2003) Behaviorally active doses of the CB1 receptor antagonist SR 141716A increase brain serotonin and dopamine levels and turnover. Pharmacol Biochem Behav 75:777787.

De Luca MA, Valentini V, Bimpisidis Z, Cacciapaglia F, Caboni P, Di Chiara G (2014) Endocannabinoid 2-arachidonoylglycerol self-administration by sprague-dawley rats and stimulation of in vivo dopamine transmission in the nucleus accumbens shell. Front Psychiatry 5:140.

De Petrocellis L, Di Marzo V (2010) Non-CB1, non-CB2 receptors for endocannabinoids, plant cannabinoids, and synthetic cannabimimetics: focus on G-protein-coupled receptors and transient receptor potential channels. J Neuroimmune Pharmacol 5:103-121.

De Petrocellis L, Bisogno T, Maccarrone M, Davis JB, Finazzi-Agro A, Di Marzo V (2001) The activity of anandamide at vanilloid VR1 receptors requires facilitated transport across the cell membrane and is limited by intracellular metabolism. J Biol Chem 276:12856-12863.

Desai C, Garriga G, McIntire SL, Horvitz HR (1988) A genetic pathway for the development of the Caenorhabditis elegans HSN motor neurons. Nature 336:638-646.

Di Marzo V, Maccarrone M (2008) FAAH and anandamide: is 2-AG really the odd one out? Trends Pharmacol Sci 29:229-233.

Di Marzo V, Bisogno T, Melck D, Ross R, Brockie H, Stevenson L, Pertwee R, De Petrocellis L (1998) Interactions between synthetic vanilloids and the endogenous cannabinoid system. FEBS Lett 436:449-454.

Engleman EA, Katner SN, Neal-Beliveau BS (2016) Caenorhabditis elegans as a model to study the molecular and genetic mechanisms of drug addiction. Prog Mol Biol Transl Sci 137:229-252.

Esposito G, Di Schiavi E, Bergamasco C, Bazzicalupo P (2007) Efficient and cell specific knock-down of gene function in targeted C. elegans neurons. Gene 395:170-176.

Ezak MJ, Ferkey DM (2010) The C. elegans D2-like dopamine receptor DOP-3 decreases behavioral sensitivity to the olfactory stimulus 1-octanol. PLoS One 5:e9487.

Ezcurra M, Tanizawa Y, Swoboda P, Schafer WR (2011) Food sensitizes C. elegans avoidance behaviours through acute dopamine signalling. EMBO J 30:1110-1122.

Fitzgerald ML, Shobin E, Pickel VM (2012) Cannabinoid modulation of the dopaminergic circuitry: implications for limbic and striatal output. Prog Neuropsychopharmacol Biol Psychiatry 38:21-29.

Galles C, Prez GM, Penkov S, Boland S, Porta EOJ, Altabe SG, Labadie GR, Schmidt U, Knölker HJ, Kurzchalia TV, de Mendoza D (2018) Endocannabinoids in Caenorhabditis elegans are essential for the mobilization of cholesterol from internal reserves. Sci Rep 8:6398.

Gantz SC, Bean BP (2017) Cell-autonomous excitation of midbrain dopamine neurons by endocannabinoid-dependent lipid signaling. Neuron 93:1375-1387.e2.

Glass M, Brotchie JM, Maneuf YP (1997) Modulation of neurotransmission by cannabinoids in the basal ganglia. Eur J Neurosci 9:199-203.

Gobira PH, Lima IV, Batista LA, de Oliveira AC, Resstel LB, Wotjak CT, Aguiar DC, Moreira FA (2017) N-arachidonoyl-serotonin, a dual FAAH and TRPV1 blocker, inhibits the retrieval of contextual fear memory: role of the cannabinoid CB1 receptor in the dorsal hippocampus. J Psychopharmacol 31:750-756.

Gross DW, Hamm J, Ashworth NL, Quigley D (2004) Marijuana use and epilepsy: prevalence in patients of a tertiary care epilepsy center. Neurology 62:2095-2097. 
Grotenhermen F, Müller-Vahl K (2012) The therapeutic potential of cannabis and cannabinoids. Dtsch Arztebl Int 109:495-501.

Haney M, Gunderson EW, Rabkin J, Hart CL, Vosburg SK, Comer SD, Foltin RW (2007) Dronabinol and marijuana in HIV-positive marijuana smokers. caloric intake, mood, and sleep. J Acquir Immune Defic Syndr 45:545-554.

Harris GP, Hapiak VM, Wragg RT, Miller SB, Hughes LJ, Hobson RJ, Steven R, Bamber B, Komuniecki RW (2009) Three distinct amine receptors operating at different levels within the locomotory circuit are each essential for the serotonergic modulation of chemosensation in Caenorhabditis elegans. J Neurosci 29:1446-1456.

Harris G, Korchnak A, Summers P, Hapiak V, Law WJ, Stein AM, Komuniecki P, Komuniecki R (2011) Dissecting the serotonergic food signal stimulating sensory-mediated aversive behavior in C. elegans. PLoS One 6:e21897.

Hart AC, ed (2006) Behavior. In: WormBook. The C. elegans Research Community. E-book available at http://www.wormbook.org/chapters/ www_behavior/behavior.html.

Herkenham M, Lynn AB, Little MD, Johnson MR, Melvin LS, de Costa BR, Rice KC (1990) Cannabinoid receptor localization in brain. Proc Natl Acad Sci U S A 87:1932-1936.

Hobert O (2002) PCR fusion-based approach to create reporter gene constructs for expression analysis in transgenic C. elegans. Biotechniques $32: 728-730$.

Horvath G, Kekesi G, Nagy E, Benedek G (2008) The role of TRPV1 receptors in the antinociceptive effect of anandamide at spinal level. Pain 134: $277-284$.

Inglis PN, Ou G, Leroux MR, Scholey JM (2007) The sensory cilia of Caenorhabditis elegans. In: WormBook. The C. elegans Research Community. E-book available at http://www.wormbook.org/chapters/www_ ciliumbiogenesis.2/ciliumbiogenesis.html.

Iskedjian M, Bereza B, Gordon A, Piwko C, Einarson TR (2007) Metaanalysis of cannabis based treatments for neuropathic and multiple sclerosis-related pain. Curr Med Res Opin 23:17-24.

Kindt KS, Quast KB, Giles AC, De S, Hendrey D, Nicastro I, Rankin CH, Schafer WR (2007) Dopamine mediates context-dependent modulation of sensory plasticity in C. elegans. Neuron 55:662-676.

Kohno M, Hasegawa H, Inoue A, Muraoka M, Miyazaki T, Oka K, Yasukawa M (2006) Identification of $\mathrm{N}$-arachidonylglycine as the endogenous ligand for orphan G-protein-coupled receptor GPR18. Biochem Biophys Res Commun 347:827-832.

Komuniecki R, Harris G, Hapiak V, Wragg R, Bamber B (2012) Monoamines activate neuropeptide signaling cascades to modulate nociception in C. elegans: a useful model for the modulation of chronic pain? Invert Neurosci 12:53-61.

Kurihara J, Nishigaki M, Suzuki S, Okubo Y, Takata Y, Nakane S, Sugiura T, Waku K, Kato H (2001) 2-arachidonoylglycerol and anandamide oppositely modulate norepinephrine release from the rat heart sympathetic nerves. Jpn J Pharmacol 87:93-96.

Lauckner JE, Jensen JB, Chen HY, Lu HC, Hille B, Mackie K (2008) GPR55 is a cannabinoid receptor that increases intracellular calcium and inhibits M current. Proc Natl Acad Sci U S A 105:2699-2704.

Law W, Wuescher LM, Ortega A, Hapiak VM, Komuniecki PR, Komuniecki R (2015) Heterologous expression in remodeled C. elegans: a platform for monoaminergic agonist identification and anthelmintic screening. PLoS Pathog 11:e1004794.

Lehtonen M, Storvik M, Malinen H, Hyytiä P, Lakso M, Auriola S, Wong G, Callaway JC (2011) Determination of endocannabinoids in nematodes and human brain tissue by liquid chromatography electrospray ionization tandem mass spectrometry. J Chromatogr B Analyt Technol Biomed Life Sci 879:677-694.

Lucanic M, Held JM, Vantipalli MC, Klang IM, Graham JB, Gibson BW, Lithgow GJ, Gill MS (2011) N-acylethanolamine signalling mediates the effect of diet on lifespan in Caenorhabditis elegans. Nature 473:226-229.

Maccarrone M, Rossi S, Bari M, De Chiara V, Fezza F, Musella A, Gasperi V, Prosperetti C, Bernardi G, Finazzi-Agrò A, Cravatt BF, Centonze D (2008) Anandamide inhibits metabolism and physiological actions of 2-arachidonoylglycerol in the striatum. Nat Neurosci 11:152-159.

Martínez-Pinilla E, Reyes-Resina I, Oñatibia-Astibia A, Zamarbide M, Ricobaraza A, Navarro G, Moreno E, Dopeso-Reyes IG, Sierra S, Rico AJ, Roda E, Lanciego JL, Franco R (2014) CB1 and GPR55 receptors are co- expressed and form heteromers in rat and monkey striatum. Exp Neurol 261:44-52.

Mato S, Aso E, Castro E, Martín M, Valverde O, Maldonado R, Pazos A (2007) CB1 knockout mice display impaired functionality of 5-HT1A and 5-HT2A/C receptors. J Neurochem 103:2111-2120.

McHugh D, Page J, Dunn E, Bradshaw HB (2012) Delta(9) -tetrahydrocannabinol and $\mathrm{N}$-arachidonyl glycine are full agonists at GPR18 receptors and induce migration in human endometrial HEC-1B cells. Br J Pharmacol 165:2414-2424.

McIntosh BT, Hudson B, Yegorova S, Jollimore CA, Kelly ME (2007) Agonist-dependent cannabinoid receptor signalling in human trabecular meshwork cells. Br J Pharmacol 152:1111-1120.

McLaughlin RJ, Hill MN, Gorzalka BB (2009) Monoaminergic neurotransmission contributes to cannabinoid-induced activation of the hypothalamic-pituitary-adrenal axis. Eur J Pharmacol 624:71-76.

Mills H, Hapiak V, Harris G, Summers P, Komuniecki R (2012) The interaction of octopamine and neuropeptides to slow aversive responses in C. elegans mimics the modulation of chronic pain in mammals. Worm 1:202-206.

Mills H, Ortega A, Law W, Hapiak V, Summers P, Clark T, Komuniecki R (2016) Opiates modulate noxious chemical nociception through a complex monoaminergic/peptidergic cascade. J Neurosci 36:5498-5508.

Morisset V, Ahluwalia J, Nagy I, Urban L (2001) Possible mechanisms of cannabinoid-induced antinociception in the spinal cord. Eur J Pharmacol 429:93-100

Nurrish S, Ségalat L, Kaplan JM (1999) Serotonin inhibition of synaptic transmission: Galpha( 0 ) decreases the abundance of UNC-13 at release sites. Neuron 24:231-242.

Oakes MD, Law WJ, Clark T, Bamber BA, Komuniecki R (2017) Cannabinoids activate monoaminergic signaling to modulate key C. elegans behaviors. J Neurosci 37:2859-2869.

Ohno-Shosaku T, Kano M (2014) Endocannabinoid-mediated retrograde modulation of synaptic transmission. Curr Opin Neurobiol 29:1-8.

Overton HA, Babbs AJ, Doel SM, Fyfe MC, Gardner LS, Griffin G, Jackson HC, Procter MJ, Rasamison CM, Tang-Christensen M, Widdowson PS, Williams GM, Reynet C (2006) Deorphanization of a G protein-coupled receptor for oleoylethanolamide and its use in the discovery of smallmolecule hypophagic agents. Cell Metab 3:167-175.

Pacher P, Bátkai S, Kunos G (2006) The endocannabinoid system as an emerging target of pharmacotherapy. Pharmacol Rev 58:389-462.

Pastuhov SI, Matsumoto K, Hisamoto N (2016) Endocannabinoid signaling regulates regenerative axon navigation in Caenorhabditis elegans via the GPCRs NPR-19 and NPR-32. Genes Cells 21:696-705.

Pertovaara A (2006) Noradrenergic pain modulation. Prog Neurobiol 80: 53-83.

Pertwee RG (2005) Inverse agonism and neutral antagonism at cannabinoid CB1 receptors. Life Sci 76:1307-1324.

Reis Rodrigues P, Kaul TK, Ho JH, Lucanic M, Burkewitz K, Mair WB, Held JM, Bohn LM, Gill MS (2016) Synthetic ligands of cannabinoid receptors affect dauer formation in the nematode Caenorhabditis elegans. G3 (Bethesda) 6:1695-1705.

Romero TR, Resende LC, Guzzo LS, Duarte ID (2013) CB1 and CB2 cannabinoid receptor agonists induce peripheral antinociception by activation of the endogenous noradrenergic system. Anesth Analg 116:463-472.

Ryberg E, Larsson N, Sjögren S, Hjorth S, Hermansson NO, Leonova J, Elebring T, Nilsson K, Drmota T, Greasley PJ (2007) The orphan receptor GPR55 is a novel cannabinoid receptor. Br J Pharmacol 152:10921101.

Sagredo O, Ramos JA, Fernández-Ruiz J, Rodríguez ML, de Miguel R (2006) Chronic Delta9-tetrahydrocannabinol administration affects serotonin levels in the rat frontal cortex. Naunyn Schmiedebergs Arch Pharmacol 372:313-317.

Sanyal S, Wintle RF, Kindt KS, Nuttley WM, Arvan R, Fitzmaurice P, Bigras E, Merz DC, Hébert TE, van der Kooy D, Schafer WR, Culotti JG, Van Tol HH (2004) Dopamine modulates the plasticity of mechanosensory responses in Caenorhabditis elegans. EMBO J 23:473-482.

Sawin ER, Ranganathan R, Horvitz HR (2000) C. elegans locomotory rate is modulated by the environment through a dopaminergic pathway and by experience through a serotonergic pathway. Neuron 26:619-631.

Sokolchik I, Tanabe T, Baldi PF, Sze JY (2005) Polymodal sensory function of the Caenorhabditis elegans OCR-2 channel arises from distinct intrinsic 
determinants within the protein and is selectively conserved in mammalian TRPV proteins. J Neurosci 25:1015-1023.

Starowicz K, Nigam S, Di Marzo V (2007) Biochemistry and pharmacology of endovanilloids. Pharmacol Ther 114:13-33.

Steffens M, Feuerstein TJ (2004) Receptor-independent depression of DA and 5-HT uptake by cannabinoids in rat neocortex-involvement of $\mathrm{Na}(+) / \mathrm{K}(+)$-ATPase. Neurochem Int 44:529-538.

Sulston J, Dew M, Brenner S (1975) Dopaminergic neurons in the nematode Caenorhabditis elegans. J Comp Neurol 163:215-226.

Suo S, Sasagawa N, Ishiura S (2003) Cloning and characterization of a Caenorhabditis elegans D2-like dopamine receptor. J Neurochem 86:869878.

Svendsen KB, Jensen TS, Bach FW (2004) Does the cannabinoid dronabinol reduce central pain in multiple sclerosis? Randomised double blind placebo controlled crossover trial. BMJ 329:253.

Sze JY (2007) The TRPV channel in C. elegans serotonergic neurons. In: TRP ion channel function in sensory transduction and cellular signaling cascades (Liedtke WB, Heller S, eds). Boca Raton, FL: CRC.

Tobin DM, Madsen DM, Kahn-Kirby A, Peckol EL, Moulder G, Barstead R, Maricq AV, Bargmann CI (2002) Combinatorial expression of TRPV channel proteins defines their sensory functions and subcellular localization in C. elegans neurons. Neuron 35:307-318.

Togashi K, Inada H, Tominaga M (2008) Inhibition of the transient receptor potential cation channel TRPM2 by 2 -aminoethoxydiphenyl borate (2-APB). Br J Pharmacol 153:1324-1330.
Tsou K, Nogueron MI, Muthian S, Sañudo-Pena MC, Hillard CJ, Deutsch DG, Walker JM (1998) Fatty acid amide hydrolase is located preferentially in large neurons in the rat central nervous system as revealed by immunohistochemistry. Neurosci Lett 254:137-140.

Wang H, Treadway T, Covey DP, Cheer JF, Lupica CR (2015) Cocaineinduced endocannabinoid mobilization in the ventral tegmental area. Cell Rep 12:1997-2008.

Winters BD, Krüger JM, Huang X, Gallaher ZR, Ishikawa M, Czaja K, Krueger JM, Huang YH, Schlüter OM, Dong Y (2012) Cannabinoid receptor 1-expressing neurons in the nucleus accumbens. Proc Natl Acad Sci U S A 109:E2717-E2725.

Wissel J, Haydn T, Müller J, Brenneis C, Berger T, Poewe W, Schelosky LD (2006) Low dose treatment with the synthetic cannabinoid nabilone significantly reduces spasticity-related pain: a double-blind placebocontrolled cross-over trial. J Neurol 253:1337-1341.

Xu SZ, Zeng F, Boulay G, Grimm C, Harteneck C, Beech DJ (2005) Block of TRPC5 channels by 2-aminoethoxydiphenyl borate: a differential, extracellular and voltage-dependent effect. Br J Pharmacol 145:405-414.

Zhang S, Sokolchik I, Blanco G, Sze JY (2004) Caenorhabditis elegans TRPV ion channel regulates $5 \mathrm{HT}$ biosynthesis in chemosensory neurons. Development 131:1629-1638.

Zygmunt PM, Ermund A, Movahed P, Andersson DA, Simonsen C, Jönsson BA, Blomgren A, Birnir B, Bevan S, Eschalier A, Mallet C, Gomis A, Högestätt ED (2013) Monoacylglycerols activate TRPV1—a link between phospholipase C and TRPV1. PLoS One 8:e81618. 